\title{
USING THE SCOUT METHOD IN HEALTHCARE SOFTWARE ENGINEERING
}

\author{
José L. Pastrana, PhD \\ University of Malaga, Spain
}

\begin{abstract}
European universities are involved in a process of change to ensure they are more comparable, compatible and coherent systems of higher education inside the European Higher Education Area (EHEA). In addition, scouting takes more than 100 years educating young people around the world. This non-formal education is based on values and its method is near the same for more than 30 million people along more than 100 years. The main goal of this paper is to show the analogy and the relationship between the educational model proposed by scouting and the educational model proposed by the EHEA, as well as to present a real case study where the scout method has been implemented in a health care software engineering subject at the informatics and computer science school in the University of Malaga. Along this paper, educational models, their analogies and relationships will be presented. Finally, the case study will be presented, developed and evaluated.
\end{abstract}

Keywords: European space for higher education; scout method; Healthcare computer engineering education

\section{European Higher Education Area}

The European Higher Education Area (EHEA) was launched along with the Bologna Process (The European Higher Education Area., 2010) decade anniversary, in March 2010, during the Budapest-Vienna Ministerial Conference. As the main objective of the Bologna Process since its inception in 1999, the EHEA was meant to ensure more comparable, compatible and coherent systems of higher education in Europe. Between 1999 and 2010, all the efforts of the Bologna Process members were targeted to creating the European Higher Education Area, that became reality with the BudapestVienna Declaration of March, 2010.

In many respects, the Bologna Process has been revolutionary for cooperation in European higher education (Secretariat, 2009). Four education ministers participating in the celebration of the 800th anniversary of the 
University of Paris (Ministers in charge for France, 1998) shared the view that the segmentation of the European higher education sector in Europe was outdated and harmful. The decision to engage in a voluntary process to create the European Higher Education Area (EHEA) was formalized one year later in Bologna, by 30 countries (Education, 1999). It is now apparent that this was a unique undertaking as the process today includes no fewer than 47 participating countries, out of the 49 countries that have ratified the European Cultural Convention of the Council of Europe (1954).

At its inception, the Bologna Process was meant to strengthen the competitiveness and attractiveness of the European higher education and to foster student mobility and employability through the introduction of a system based on undergraduate and postgraduate studies with easily readable programs and degrees. Quality assurance has played an important role from the outset, too.

However, the various ministerial meetings since 1999 have broadened this agenda and have given greater precision to the tools that have been developed. The undergraduate/postgraduate degree structure has been modified into a three-cycle system, which now includes the concept of qualifications frameworks, with an emphasis on learning outcomes. The concept of social dimension of higher education has been introduced and recognition of qualifications is now clearly perceived as central to the European higher education policies. In brief, the evolution of the main objectives of the Bologna Process can be seen hereby (Zgaga, 2006).

The Sorbonne Declaration was signed in 1998, by the ministers of four countries, namely France, Germany, United Kingdom and Italy. The aim of the Declaration was to create a common frame of reference within the intended European Higher Education Area, where mobility should be promoted both for students and graduates, as well as for the teaching staff. Also, it was meant to ensure the promotion of qualifications, with regard to the job market.

The aims of the Sorbonne Declaration were confirmed in 1999, through the Bologna Declaration, where 29-30 countries expressed their willingness to commit to enhance the competitiveness of the European Higher Education Area, emphasizing the need to further the independence and autonomy of all Higher Education Institutions. All the provisions of the Bologna Declaration were set as measures of a voluntary harmonization process, not as clauses of a binding contract.

As follow-up to the Bologna Declaration, there have taken place Ministerial Conferences every two years, the ministers expressing their will through the respective Communiqués. With the Prague Communiqué, in 2001, the number of member countries was enlarged to 33, and there has also taken place an expansion of the objectives, in terms of lifelong learning, 
involving students as active partners and enhancing the attractiveness and competitiveness of the European Higher Education Area. Also, the participating ministers committed themselves to ensure the further development of quality assurance and development of national qualification frameworks. This objective was correlated with the lifelong learning one, as it is considered an important element of higher education that must be taken into consideration when building up new systems. Also, it is important to mention that the topic of social dimension was first introduced in the Prague Communiqué.

The following Ministerial Conference took place in Berlin, in 2003, thus the Berlin Communiqué enlarging the number of countries to 40 members. The main provisions of this Communiqué dealt with an expansion of the objectives, in terms of promotion of linking European Higher Education Area to European Research Area, as well as the promotion of quality assurance. Another important aspect that the Berlin Communiqué stated referred to establishing the follow-up structures supporting the process in-between two Ministerial meetings. This arrangement established the Bologna Follow-up Group, the Board and the Bologna Secretariat. With this Communiqué the Ministers also agreed that there should be created a national follow-up structure in each of the participating countries.

The Bergen Communiqué, of 2005, underlined the importance of partnerships, including stakeholders - students, HEIs, academic staff and employers, together with the further enhancing of research, especially with regard to the third cycle - doctoral programs. Also, this Communiqué stressed the ministers' will to provide a more accessible higher education, together with an increased attractiveness of the EHEA to other parts of the world.

With the London Communiqué, of 2007, the number of participating countries was enlarged to 46. This Communiqué focused on evaluating the progress achieved by that time, concerning mobility, degree structure, recognition, qualifications frameworks (both overarching and national), lifelong learning, quality assurance, social dimension, and also set the priorities for 2009, these being, mainly, mobility, social dimension, which was defined here for the first time, data collection, employability, EHEA in a global context and stock taking. For 2010 and beyond, it was stressed that there is the need for further collaboration, seeing it as an opportunity to reformulate the visions and values.

In the Leuven/Louvain-la-Neuve Communiqué, of 2009, the main working areas for the next decade were set, with emphasis on: social dimension, lifelong learning, employability, student centred learning and the teaching mission of education, international openness, mobility, education, research \& innovation, as well as data collection, funding of the HE and 
multidimensional transparency tools. These main working areas show a new orientation of the Bologna Process, towards a more in-depth approach of the reforms, thus ensuring the completion of the Bologna Process implementation. Another change, in terms of internal arrangements, referred to the Bologna Process Chairing procedure: from a previous situation where the Bologna Process had been chaired by the country holding the EU Presidency, to a situation according to which the Process is being chaired by two countries: both the country holding the EU Presidency and a non-EU country, named in alphabetical order, starting from July 1st, 2010.

The following Ministerial Conference took place only one year after the aforementioned, more precisely in March 2010. It took place in Budapest-Vienna and it was an Anniversary Conference, celebrating a decade of the Bologna Process. With this occasion, there took place the official launching of the European Higher Education Area, which meant that, in terms of a common European framework for HE, the objective set in the Bologna Declaration was accomplished.

However, the existence of the European Higher Education Area in itself did not mean an achievement of all the objectives agreed upon by the ministers involved in the Bologna Process. Therefore, we can now say that the Bologna Process and the European Higher Education Area have entered a new phase, namely the consolidation and operationalization one, especially in light of the very different reactions to the Bologna Process implementation across Europe.

Also, starting with the Budapest-Vienna Ministerial Conference, the EHEA has been expanded to 47 countries; the most recently admitted being Kazakhstan. The main message of the Bucharest Ministerial Conference, which took place on 26 - 27 April 2012 and was attended by 47 European ministers responsible for higher education, states that Higher education reform can help to get Europe back on track and generate sustainable growth and jobs. The Ministers agreed to focus on three main goals in the face of the economic crisis: to provide quality higher education to more students, to better equip students with employable skills, and to increase student mobility. The 47 countries adopted a new European strategy to increase mobility with a specific target that at least 20 percent of those graduating in Europe in 2020 should have been on a study or training period abroad.

Besides the Ministerial Conferences, there are also Bologna Policy Forum organized, which were so far coupled with the EHEA Ministerial Conferences.

The first Bologna Policy Forum was organized in Leuven/Louvainla-Neuve in 2009 and it was attended by the 46 members of the Bologna Process, at the time, as well as a wide range of third countries and NGOs. The main issues agreed upon by the participants were the following: the key 
role that HE plays in the development of the society, based on lifelong learning and equitable access at all levels of society to learning opportunities, the importance of public investment in higher education, in spite of the economic crisis, transnational exchanges in higher education should be governed on the basis of academic values, advocating a balanced exchange of teachers, researchers and students between countries, in order to promote fair and fruitful "brain circulation", as an alternative to brain drain.

The Second Bologna Policy Forum took place in Vienna, in March 2010, and it was attended by the 47 members and the eight consultative members, as well as third countries and other relevant NGOs. The main topics of discussion included in the Second Bologna Policy Forum Statement refer to the manner in which higher education systems and institutions respond to the growing demands and multiple expectations and the balance between cooperation and competition in international higher education. This Forum's Statement also included some possible concrete feedback to be taken up by the participants, such as nominating contact persons for each participating country which will also function as liaison points for a better flow of information and joint activities, including the preparation of the next Bologna Policy Forum at ministerial level. Also the need for supporting global student dialogue was acknowledged.

As far as implementation is concerned, progress over the years has been uneven, as can be seen from the various stocktaking exercises. This shows that the reforms of the Bologna Process must still be furthered, in order to ensure more comparable, compatible and coherent systems of higher education in Europe.

If by 2010, the main aim of the Bologna Process was to put in place a European Higher Education Area, as stated in the Leuven/Louvain-la-Neuve Communiqué, the main priorities for the next decade are:

- Social dimension

- $\quad$ Lifelong learning

- Employability

- $\quad$ Student-centered learning

- Education, research and innovation

- Mobility

- Data collection

- Multidimensional transparency tools

- Funding.

Therefore, the Bologna Follow-up Group set up the following working groups for the 2009-2012 period:

- $\quad$ Social dimension

- $\quad$ Qualifications frameworks

- International openness 
- $\quad$ Mobility

- Recognition

- $\quad$ Reporting on the implementation of the Bologna Process

- $\quad$ Transparency mechanisms,

- $\quad$ And the following networks:

- $\quad$ EHEA Information and Promotion Network;

- $\quad$ Network for Experts in Student Support in Europe - NESSIE;

- Network for National Qualifications Frameworks Correspondents.

Now, after the launching of the European Higher Education Area, the Bologna Process moves towards a new phase, a more in-depth one, focusing on a reduction of the implementation discrepancies in the countries forming the EHEA.

The next milestone of the European Higher Education Area has been marked at the EHEA Ministerial Conference, which took place in Bucharest, Romania, on 26-27 April 2012. The Third Bologna Policy Forum, which was organized in conjunction to this Ministerial meeting contributed to further the debate on the progress of the European Higher Education Area on the global scale. It was attended by members and heads of delegations from 47 EHEA countries and 19 non-EHEA countries along with representatives of international organizations from the field of higher education.

The overarching theme of the third Bologna Policy Forum was "Beyond the Bologna Process: Creating and connecting national, regional and global higher education spaces". The third edition of the Bologna Policy Forum focused on creating and connecting national, regional and global higher education spaces, while deepening the discussions on the following four topics reflecting on future approaches for dialogue in this context:

- $\quad$ Public responsibility for and of higher education within national and regional context;

- Global academic mobility: Incentives and barriers, balances and imbalances;

- Global and regional approaches to quality enhancement of higher education;

- The contribution of $\mathrm{HE}$ reforms to enhancing graduate employability;

The participants stated that the BPF concept should be further enriched and taken forward in order to maximize its potential for policy dialogue. In this sense, an evaluation of the Bologna Policy Forum was organized immediately after the event with all participant delegations. 


\section{The Aims and Method of Scouting}

The Scout method is the informal educational system used by Scouting. Non-formal education is the organized educational activity outside the established formal system that is intended to serve an identifiable learning clientele with identifiable learning objectives" (UNESCO).

The Scout Method is a system of progressive self-education through (Scouting an Educational System, 1998):

- A promise and law.

- $\quad$ Learning by doing.

- Membership of small groups (for example the patrol), involving, under adult guidance, progressive discovery and acceptance of responsibility and training towards self-government directed towards the development of character, and the acquisition of competence, self-reliance, dependability and capacities both to cooperate and to lead.

- $\quad$ Progressive and stimulating programs of varied activities based on the interests of the participants, including games, useful skills, and services to the community, taking place largely in an outdoor setting in contact with nature.

The aim of Scouting is character training with the goal of helping participants become independent and helpful, and thereby become "healthy, happy, helpful citizens”. The Scout method uses appealing games in the primitive outdoors to generate challenges which a Scout learns to solve by himself. Through the training and the example of the leader, Scouts are taught independence, leadership, the ambition to learn by himself/herself, and a moral code with positive goals. According to founder Robert BadenPowell (Baden-Powell, 1908), the Scout method works naturally and unconsciously: naturally in the way that it follows the natural impulses of the Scout, and unconsciously because the Scout is not aware of the education. Hands-on orientation provides a practical method of learning and helps the Scout build confidence. Activities and games provide a fun way to develop skills and provide contact with nature and the environment when pursued in an outdoor setting. Scouts learn in small groups to build unity and a brotherly atmosphere. Developing the characteristics of responsibility, self-reliance, self-confidence, and readiness, the Scouts eventually learn collaboration and leadership skills. An attractive program of varying activities expands a Scout's horizons and bonds the Scout even more to the group.

The Scouting program has three specific objectives, commonly referred to as the "Aims of Scouting." They are character development, citizenship training, and personal fitness. The methods by which the aims are achieved are listed below in random order to emphasize the equal importance of each (The World Programme Policy, 1990). 
Ideals: The ideals of Scouting are spelled out in the Scout Oath, the Scout Law, the Scout motto, and the Scout slogan (World Scout Bureau, 2011). The Scout measures himself against these ideals and continually tries to improve. The goals are high, and, as he reaches for them, he has some control over what and who he becomes.

Patrols: The patrol method gives Scouts an experience in group living and participating citizenship. It places responsibility on young shoulders and teaches boys and girls how to accept it. The patrol method allows Scouts to interact in small groups where they can easily relate to each other. These small groups determine troop activities through their elected representatives.

Outdoor Programs: Scouting is designed to take place outdoors. It is in the outdoor setting that Scouts share responsibilities and learn to live with one another. It is here that the skills and activities practiced at troop meetings come alive with purpose. Being close to nature helps Scouts gain an appreciation for God's handiwork and humankind's place in it. The outdoors is the laboratory for Scouts to learn ecology and practice conservation of nature's resources.

Advancement: Scouting provides a series of surmountable obstacles and steps in overcoming them through the advancement method. The Scout plans his/her advancement and progresses at his/her own pace as he/she meets each challenge. The Scout is rewarded for each achievement, which helps him/her gain self-confidence. The steps in the advancement system help a Scout grow in self-reliance and in the ability to help others.

Association with Adults: Boys and girls learn a great deal by watching how adults conduct themselves. Scout leaders can be positive role models for the members of their troops. In many cases a Scoutmaster who is willing to listen to children, encourage them, and take a sincere interest in them can make a profound difference in their lives.

Personal Growth: As Scouts plan their activities and progress toward their goals, they experience personal growth. The Good Turn concept is a major part of the personal growth method of Scouting. Children grow as they participate in community service projects and do Good Turns for others. Probably no device is so successful in developing a basis for personal growth as the daily Good Turn. The religious emblems program also is a large part of the personal growth method. Frequent personal conferences with his Scoutmaster help each Scout to determine his/her growth toward Scouting's aims.

Leadership Development: The Scout program encourages young people to learn and practice leadership skills. Every Scout has the opportunity to participate in both shared and total leadership situations. 
Understanding the concepts of leadership helps a boy accept the leadership role of others and guides him toward the citizenship aim of Scouting.

Uniform: The uniform makes the Scout troop visible as a force for good and creates a positive youth image in the community. Scouting is an action program, and wearing the uniform is an action that shows each Scout's commitment to the aims and purposes of Scouting. The uniform gives the Scout identity in a world brotherhood of youth who believe in the same ideals. The uniform is practical attire for Scout activities and provides a way for Scouts to wear the badges that show what they have accomplished.

\section{The Analogy between EHEA and the Scout Method}

The Scout Method provides an educational framework based upon how young people develop naturally. It provides an environment which responds to:

- $\quad$ their need for action, challenge and adventure;

- $\quad$ their desire to explore, experiment, and discover;

- $\quad$ their natural capacity for inventiveness and resourcefulness;

- $\quad$ the need to feel acknowledged, respected and appreciated as individuals;

- $\quad$ their need for close supportive relationships;

- their capacity for idealism and their need to make sense of the world;

Following, we will show a set of teaching parameters used to evaluate the quality of the university education and their values in the traditional university, the EHEA and the scouting.

Size of the Group: Traditional University uses a large group (one hundred or more students) in a big classroom. However, the EHEA believes it is better to use smaller groups and recommend less than 50 students in theory lesson class and 25 in practical one. It sounds interesting that scouting promotes learning by "living in small groups" as one of the principles of the Scout method.

Knowledge Evaluation: Traditional University requires lectures or exams to evaluate Knowledge, Skills, and Abilities. The EHEA prefer along semester evaluations because while end-of-semester evaluations provide a quantitative analysis of class instruction, they may provide little direct feedback and they can be influenced by punctually personal moments. On that way, the Scout method believes each activity done has to be evaluated and celebrated.

Teaching Method: Traditional University uses the master class as the main way to teach. In the opposite side, the EHEA goes in the way of a curriculum based on team-oriented, project-based, and learning-by-doing. 
And the Scout Method provides an educational framework based on learning-by-doing and long-life-learning.

Workload: Workload in the traditional University means how many hours the teacher is in the classroom. The EHEA takes the point of view of the students. So, the workload will mean how many hours a medium student will be working. This new measure takes into account lessons time, studying time, researching time, group meeting time, etc. One of the aims of Scouting is to offer attractive and fascinating activities to the children to be taken in their free time and which means no workload for them.

Curricula Model: The curricular model used in the traditional University is based on knowledge, so they try to establish what the student has to know. The EHEA focus its curricular model in competences, so they try to establish what the student is able to do. And finally, the model used by scouts is centre in values, what it means how we want the people be.

\section{A Real Experience}

A real experience has been developed during last year. It has taken the principles of scout method (living in small groups, team-oriented, project-based, learning-by-doing, and long-life-learning) and applied for the Healthcare Software Engineering subject development and implementation.

This is a first semester (from September to February) in the third year of the grade. It is 6 ECTS subject what it means 150 hours working time for a student where 60 hours are in-person class. The main goal of this subject is to offer a general view about software developing in the field of healthcare system such us Electronic Health Records, Clinical decision support, telemedicine, etc.

The list of topics is as follow:

1. Healthcare system Design.

2. Hospital Information Systems.

3. Electronic Health Records Design.

4. Medical Equipment and Applications.

5. Clinical decision support.

6. Information Security.

There were 17 students in the group what it allowed learning by "living in small groups" (Size of the Group). The evaluation process has been taken along the course by a set of weekly practice at the laboratory, a researching work in small groups (4 people), knowledge weekly tests and a final exam (Knowledge Evaluation). The laboratory practices were a projectbased and learning-by-doing project where the students have had to develop a small hospital information system step by step improving it each week (Teaching Method). This way, the students have had to work day by day in 
an attractive project related to they want to work in the future (Workload and Curricula Model).

After the semester ended the results of the case study where amazing. All the students passed the subject and all of them were very happy with the method used.

The official Scores have been:

\begin{tabular}{|c|c|}
\hline Mark & Number of Students \\
\hline Not presented & 0 \\
\hline Fail (F) & 0 \\
\hline Pass (C) & 5 \\
\hline Pass (B) & 5 \\
\hline Pass (A) & 6 \\
\hline Pass (A++) & 1 \\
\hline
\end{tabular}

\section{Healthcare Software Engineer}

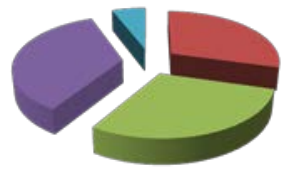

\section{Conclusion and Future Work}

Along this paper, the reader can see how the model proposed by the EHEA in the 21st century goes on the same way that the scout models proposed one hundred years ago (in 1907).

We think that the real experience has been highly positive and very motivating, and we also think that the scouts groups could work together in a symbiosis with the university in order to prepare the future students that will go to the university as "healthy, happy, helpful citizens" and then those students could return to the scouts groups as leaders and returning the values they got.

As future work, we are going to continue using the scout method as the methodology used in several EHEA subjects. We think it could be very interesting that an agreement will be sign among the university and the scouts groups in order to include the work as voluntary that a lot of students do in the scouts groups as a part of their university curriculum, as well as offering the scouts activities to the university community in two ways: in one hand to the students for working as voluntaries and in other hand to the children of the university community (teachers, students, maintenance service, etc.).

\section{References:}

Baden-Powell, R. (1908). Scouting For Boys. London, United Kingdom: Horace Cox.

(2011). Constitution of the World Organization of the Scout Movement. World Scout Bureau.

(1998). Scouting an Educational System. World Scout Bureau.

Secretariat, B. B. (2009). BOLOGNA beyond 2010. Leuven. (1998). The Essential Characteristics of Scouting. World Scout Bureau. 
(2010). The European Higher Education Area. Austrian Federal Ministry of Science and Research.

(1990). The World Programme Policy. World Scout Bureau.

Zgaga, P. (2006). Looking out: The Bologna Process in a Global Setting. Austrian Federal Ministry of Science and Research. 